features are two mountain ranges, running pretty well parallel to each other from east to west. The northernmost of these two ranges extends almost the whole length of the island from Cape Kormakiti on the north-west to Cape St. Andrea at the end of the horn-like promontory which stretches for 40 miles from the north-east of the island. This promontory is called the Carpas, and the low mountain chain running through it is called the Carpas range. The westernmost and higher portion of the northern range is called the Kyrenia range, and rises to an altitude of 3340 feet. This range is of a remarkably picturesque outline, in some parts extremely rugged. It is mostly a single ridge without any remarkable spurs, and its summit is about two miles from the northern coast. It can be crossed in many places. The chief mountain peaks of this range are Kornos, 3105 feet; Buffavento, 3140; and Pentedaktylos, 2400. The last named is a remarkably shaped rock in the centre of the Kyrenian range, owing its name to its shape, the word Pentedaktylos signifying in Greek "five-fingered." Beneath this rock there rushes out southward from the mountain side, at an altitude of 870 feet, a torrent of water, which never ceases to flow summer or winter, and which, descending into the great plain in the centre of the island, carries its fertilizing streams to the lands of several villages, its course marked by mills, gardens, and trees, until its water is exhausted by various irrigating channels. A similar stream of water gushes from the northern side, about $\mathbf{I} 2$ miles west of the Kyrenia Pass. Smaller streams descend on either side of the range at various places; their waters are used for irrigation in the valleys. The southern range of mountains is of a much more extensive nature than the northern range. The easternmost point of this range is the mountain of Santa Croce, so called from the church of the Holy Cross which stands on its summit. This mountain, which is 2260 feet in height, is of a peculiar shape. Beginning then from this point the southern range rapidly rises to considerable altitudes, finally culminating in Mount Troodos, the highest point in Cyprus, being 6406 feet above the sea-level. The other chief peaks in the southern range, are Adelphe, 5305 feet ; and Machera, 4674 feet. But it is not only in altitude that the Troodos range is distinguished; numerous spurs run down to the north and south, and as we proceed further west these radiate out to greater distances, so that half way between Troodos and the sea, the mountain range is not less than 20 miles wide. Here there are very considerable forests, many miles in extent, rarely visited save by wandering flocks and by wood-cutters, and affording shelter to the moutflon, or wild sheep of Europe, some 200 or 300 of which still roam over these hills. On the map it will be seen that numerous rivers descend from both sides of the southern range. These are mostly dry in summer, but after rain their waters descend with violence, filling up the river-beds in the plains, carryiny away trees and cultivated patches, and often rushing in a turbid stream into the bays of Famagusta and Morphou. Between the two mountain ranges there lies a great plain called the Mesaorea, which is the most fertile part of Cyprus, growing large crops of wheat, barley, and cotton. It was evidently once the bottom of the sea, for in many parts are large beds of marine shells-gigantic oysters and others-all clustered in masses. A noticeable feature of this plain is the number of flat-topped plateaux of various sizes, where the rock seems to have resisted the action of the water. 'The tops of these plateaux are clothed with short herbage, affording a scanty provision for flocks, an 1 are usually from 100 to 200 feet above the plain. The rivers which descend from the hills carry down large quantities of alluvial soil, and this forms in the eastern part of the Mesaorea a rich deposit, something similar to the Delta of the Nile. The two rivers which mainiy contribute to this plain are the Pediæus and the Idalia, the former taking its rise from the northern slopes of Mount Machera, and the latter from the eastern slopes of the same mountain. The beds of these rivers have, however, become so choked up with alluvial deposit towards the end of their course, that their waters overflow the plain and mingle together, so that their separate mouths can with difficulty be distinguished. The jormal condition of these rivers is to be without water, but whenever there is a heavy rainfall in the mountains, the river "comes down," as it is called, and runs for one, two, or more days. It occasionally happens that the water descends with great suddenness and violence, causing disastrous floods. Considerable supplies of water for irrigation purposes are obtained by sinking wells. A long chain of wells are sunk at distances of five or six yards apart, and being connected by underground galleries, a channel is thus formed which conveys the water to a reservoir constructed at the foot of the last well, and it is thence raised to the surface by a water-wheel; or in some cases the level of the ground admits of the channel being brought out on the surface. In this way the town of Nicosia is supplied with excellent water, which is brought in two aqueducts from a distance of some miles. Larnaca and Famagusta and other towns have similar aqueducts. Closely connected with the water supply is the forest question. Sir Robert Biddulph then entered into detail with reference to the denudation of Cyprus of its forests, and the great locustplagues which have been so successfully treated since the British occupation.

\section{THE FLORA OF CHINA.}

SINCE the last meeting of the British Association, two additional parts of the "Index Floræ Sinensis" have been published, bringing the enumeration of known, and the descrip. tion of new, species as far as the Loganiacea. The Committee now, therefore, look forward with some confidence to the completion of their labours at no distant date.

Further extensive and valuable collections have been received from China in aid of the work, more especially from Dr. Augus. tine Henry, late of Ichang. The novelty and richness of the material obtained by this indefatigable botanist far exceeds any expectations the Committee could have formed. It is to be regretted that his duties as an officer of the Chinese Imperial Maritime Customs have necessitated his removal to Hainan. It is probable, however, that he had practically exhausted the immediate neighbourhood of Ichang, and that without opportunities of travelling over a wider radius, which the Committtee regret they were unable to procure for him, he would not have been able to add much of material novelty to the large collections already transmitted by him to Kew.

The Committee have met with the kindest sympathy and assistance in their labours from Dr. C. J. de Maximowicz, of the Académie Impériale of St. Petersburg, who has long been engaged on the elaboration of the collections made by Russian travellers in China, and from M. Franchet, of the Muséum d'Histoire Naturelle at Paris, who is describing and publishing the extremely rich collections made by the French missionaries in Yunnan.

The Committee have received striking proofs of the appreciation of their labours by botanists of all countries. They permit themselves to quote the following passage from a letter received early in the present year from Baron Richthofen, than whom no one is more competent to estimate the value of work connected with the scientific exploration of China:-

"It is of great value to have, now, a Flora of China, embodying all the species known from that country. You have evidently succeeded at Kew in getting a very complete collection. At the same time, in looking over the localities mentioned in the book, it strikes me that large portions of China are stinl unexplored botanically. There remains a splendid field for a good collector in the Tsingling Mountains, the province of Sz'chuen, and chiefly its elevated region west of Ching-tu-fu. Work in those parts will be greatly facilitated by the solid foundation laid through the work of Forbes and Hemsley."

The Committee derive an independent existence as a SubCommittee of the Government Grant Committee of the Royal Society. They are at present in possession of sufficient funds to enable them to carry on the work. They do not therefore ask for their reappointment at the hands of the British Association.

\section{SCIENTIFIC SERIALS.}

American Furnal of Science, October.-Assuming that the earth's crust rests on a layer of liquid as a floating body, Mr. Le Conte here offers an explanation of normal faults. The crust is supposed to be raised into an arch, by intumescence of the liquid, caused by steam or hydrostatic pressure ; it is thus broken by long more or less parallel fissures into oblong prismatic

Third Revort of the Comnittee, consisting of Mr. Thiselton-Dyer (Secretary), Mr. Carruthers, Mr. Ball, Pruf. Oliver and Mr. Forbes, ap pointed for the purpose of continuing the preparation of a Report on our present knowledge of the Flora of China. 
blocks, which, on relief of the tension by escape of lava or vapour, are readjusted by gravity, in new positions. The blocks may be rectangular in section, but are more likely to be rhomboidal or wedge-shaped; giving level tables with fault cliffs (as in the plateau region) in the one case, and tilted blocks with normal faults (as in the basin region) in the other. The author considers the Sierra and Wahsatch to have been formed by lateral crushing and folding; and the region between to have been arched, broken, and readjusted, as clescribed, in the end of the Tertiary.-. Two determinations of the ratio of the electromagnetic to the electrostatic unit are furnished from the Johns Hopkins University ; one made this year, by Mr. Rosa, by Maxwell's method of measuring a resistance, the other ten years ago, by Messrs. Rowland, Hall, and Fletcher, by measuring a quantity of electricity electrostatically, and then measuring it electro magnetically with a galvanometer. The former gives $v=$ $2.9993 \times 10^{10}$ centimetres per second; the latter, $2.9815 \times 10^{10}$ centimetres. It seems certain, according to Mr. Rosa, that $v$ is within a tenth per cent. of 300 million metres per second. - $\mathrm{M} \mathrm{r}$ Long continues his account of the circular polarization of certain tartrate solutions; and his experiments point to a law that the rotation of a double tartrate may be made to approach that of a neutral tartrate of either of the metals present, by addition of a salt of that metal (the effects being apparently explained by substitution).-Mr. Eldridge proposes a new grouping and nomenclature for the middle Cretaceous in America. - There are also papers on the gustatory organs of the American hare ( $\mathrm{Mr}$ Tuckerman); on the output of the non-condensing engine, as a function of speed and pressure (Mr. Nipher); and on some Florida Miocene (Mr. Langdon).

\section{SOCIETIES AND ACADEMIES. LONDON.}

Physical Society, November I.-Prof. Reinold, F.R.S. President, in the chair.-The following communications were read :- On a new electric-radiation meter, by Mr.W. G. Gregory. The meter consists of a long fine platinum wire attached to a delicate magnifying spring of the Aryton and Perry type, and stretched within a compound tube of glass and brass. At the junction between the wire and spring a small mirror is fixed. When the tube is placed parallel to a Hertz's oscillator in action, the mirror is turned in a direction indicating an extension of the wire. The arrangement is so sensitive that an elongation of प्रण $\frac{1}{010} \overline{0}$ of a $\mathrm{mm}$. can be detected, and when placed at a distance of 4 metres from the oscillator the apparent extension is such as would correspond to a change of temperature of $\mathrm{o}^{\circ} \cdot 003 \mathrm{C}$. By its aid the author has roughly verified Hertz's statements that at considerable distances the intensity of radiation varies as the inverse distance ; but before he can proceed further it is necessary to greatly increase the sensibility of the apparatus and with a view of obtaining some suggestions in this direction, he exhibited it before the Society. Prof. Perry asked if the E.M.F. required to produce the observed results had been calculated; he also believed that the sensibility might be increased by using copper instead of platinum wire, and replacing the spring by a twisted strip. Mr. Blakesley inquired whether the effect of increasing the capacity of the ends of the wire had been tried. Mr. Boys said that if the observed effect was due to rise of temperature he would like to see it measured thermally. He also thought the effect might be due to extension caused by rapid electric oscillations in some such way as the elongation of an iron bar caused by magnetization. In answer to this, Prof. S. P. Thompson said the matter had been investigated experimentally, but with negative results. Prof. Herschel suggested the use of a compound spring such as is used in Breguet's metallic thermometers. In reply, Mr. Gregory said he had estimated the E.M.F. by observing that a Leclanche cell through $50 \mathrm{obms}$ produced about the same result. No improvement in sensitiveness was obtained by using copper wire or by increasing its capacity, and attempts to measure the rise of temperature by an air thermometer had been given up as hopeless. 'The President, in thanking the author 1or his paper, congratulated him on the ingenuity and courage displayed in producing an apparatus to measure such microscopic quantities as are here involved.-On a method of driving tuning-forks electrically, by Mr. Gregory. In order to give the impulses about the middle of the stroke, the fork is arranged to make and break the primary circuit of a small transformer, the secondary circuit of which is completed through the electromagnet actuating the fork. The prongs of the fork are magnetized and receive two impulses in each period. Another device was suggested, where the prongs respectively operate contacts which successively charge and discharge a condenser thruugh the coils of the actuating magnet. Prof. S. P. Thompson sair the methods, if perfect, would be of great service, and suggested that a fork so driven be tested optically by comparison with freely vibrating one. He regarded the mercury contacts used as otjectionable, for their capillarity and adhesion would probably cause the impulses to lag behind the appointed epochs. Prof. McLeod remarked that Lissajous' figures gave a satisfactory method of testing the constancy of period, and could be readily observed without using lenses, and in reference to liquid condensers suggested by the author for his second device, saic that platinum plates in sulphtu ic acid were found to disintegrate when used for this purpose. He thought lead plates would prove suitable. Prof. Jones, who read a raper on a simila subject in March last, said he now used bowed forks, with whicl to synchronize the speed of the disk there described, and the frequency is determined by causing the disk to complete th circuit of his Morse receiver once each revolution. - On a physical basis for the theory of errors, by Mr. C. V. Burton. After pointing out that the law of error for any particula measurement depends on the nature of the conditions governin! such measurement, the author considers several simple cases, ani deduces their curves of error. A kinematic method of combin. ing two or more independent errors, each following known laws. is then described and applied, and the general formula obtained leads to Laplace's law of error in the case of an infinite num. ber of similar errors. Referring to Most Advantageous Combinations of measures, it is shown that the method of least squares is only a particular solution of the general equation, and is derived by assuming the individual errors to conform to Laplace's law. Subjective errors are next considered, and ir conclusion the author says that "the law of error in a set of observations depends on the nature of each special case, and what may be called the probable law of error is determined by our knowledge of the conditions. The combination of three or more sources of error of comparable importance gives in general a law not seriously differing from that of Laplace, so that the method of least squares will be practically the most advantage. ous, except where a single suurce of error with a very differen! law is predominant above all the rest." - A note on the behaviour of twisted strips, by Prof. J, Perry, F.R.S., had been prematurely announced by mistake, and he accordingly gave only a brief outline of the paper. In a previous communication, Prof. Ayrton and the author enunciated a working hypothesis in which the strips were imagined to be split up into pairs of filaments, each pair acting as a bifilar suspension. The resulting formula for the rotation produced by a given load did not agree with experiment, and quite recently the author had recognized why the formula was incorrect. The bifilar law they had assumed was only true for small twists, but he now saw another method of treatment by which he hoped to verify the formula derived from experiment before the next meeting. Prof. Fitzgerald reminded Prof. Perry of a method of attacking the problem suggested by the speaker some time ago, in which each filament was supposed to be wrapped round a smooth cylinder; and said that on working it out the formula was found to be very complicated. Mr. Trotter thought the pairs of strip. might be regarded as twisted ladders, and Mr. Gregory said this suggestion reduced the problem to a series of bifilar suspensions which had already been worked out.-On electrifications due to contact of gases and liquids, by Mr. J. Enright. For some time past the author has been studying the electrical phenomena attending solution, by connecting an insulated vessel in which the solution takes place with an electrometer. As a general rule, no effect is observed if nothing leaves the vessel, but when gases are produced and allowed to escape the vessel becomes charged with + or - electricity, depending on the nature of the liquid from which the gas passes into the air. As an example, when zinc is placed in hydrochioric acid, the deflection of the electrometer is in one direction whilst the liquid is chiefly acid, but decreases and reverses as more and more zinc chloride is produced. From such observations the author hopes to obtain some information relating to atomic charges. Owing to the lateness of the hour, the latter portion of the paper and the discussion on it were postponed until next meeting. 